\title{
Desempleo, crisis económica y percepción sobre la población inmigrante en el Levante español
}

\author{
Unemployment, economic crisis and perception about \\ the population immigrant in the spanish Levante
}

\author{
Javier Eloy Martínez Guirao ${ }^{1}$ \\ j.eloymartinez@um.es
}

Anastasia Téllez Infantes ${ }^{2}$

atellez@umh.es

\begin{abstract}
Resumen
Durante más de una década España vivió un auge económico basado en el sector de la construcción, que conllevó la llegada de inmigrantes procedentes de diferentes lugares del mundo. Unos en busca de oportunidades laborales, otros invirtiendo sus ahorros en la compra viviendas. Fueron años en los que la inmigración era valorada por los efectos beneficiosos para la economía. Tras el estallido de la burbuja inmobiliaria y la crisis económica las circunstancias cambiaron. El desempleo se incrementó bruscamente y muchos inmigrantes retornaron a sus países de origen. Aquellos que decidieron quedarse vieron como empeoraban sus condiciones de vida y laborales, y cómo los autóctonos los perciben ahora como competidores manifestando actitudes xenófobas hacia ellos. En este artículo nos basamos en un estudio etnográfico en una de las zonas más afectadas por la crisis en España, la Vega Baja del Segura, para indagar en estos aspectos.
\end{abstract}

\section{Palabras clave}

Representaciones, xenofobia, inmigración, cambio social, empleo.

Forma sugerida de citar: Martínez Guirao, Javier Eloy \& Téllez Infantes, Anastasia (2017). Desempleo, crisis económica y percepción sobre la población inmigrante en el Levante español. Universitas, $X V(26)$, pp. 61-86.

1 Doctor en Antropología Social por la UNED (España) y doctor en Sociología por la Universidad de Alicante (España). Profesor en el Área de Antropología Social, departamento Mixto, Universidad de Murcia (España). Orcid: 0000-0001-9460-5999.

2 Doctora en Antropología Social por la Universidad de Sevilla (España). Profesora titular en el Área de Antropología Social, departamento de Ciencias Sociales y Humanas, Universidad Miguel Hernández de Elche (España). Orcid: 0000-0001-9235-6044. 


\begin{abstract}
For over a decade, Spain experienced an economic boom based on the construction sector, which led to the arrival of immigrants from different parts of the world. Someone searching of job opportunities, others investing their savings in buying homes. In those years immigration was valued by beneficial effects for the economy. After the bursting of the housing bubble and the economic crisis circumstances changed. Unemployment increased sharply and many immigrants back to their countries. Those who decided to stay saw as worsened their living conditions and work, and how the locals perceive as competitors now manifesting xenophobic attitudes towards them. In this article we rely on an ethnographic study in one of the most affected areas by the crisis in Spain, La Vega Baja del Segura, to investigate these aspects.
\end{abstract}

\title{
Keywords
}

Representations, xenophobia, immigration, social change, employ.

\section{Introducción}

En los últimos años están teniendo lugar una serie de fenómenos a lo largo del mundo que tienen en común lo que antropológicamente denominamos como el miedo al "otro". Un "otro" que en estos casos se refiere a personas inmigrantes, que ya sea por motivos bélicos, laborales, u otras circunstancias, deciden abandonar, permanente o temporalmente, su país de residencia, en busca de una vida mejor que les permita sobrevivir tanto a ellos como a sus familias. Al llegar a su lugar de destino tienen que hacer frente, en muchas ocasiones, a la acritud de la población local, que los puede percibir con recelo, como una amenaza para su cultura y para su bienestar.

El surgimiento y el auge de movimientos "ultraderechistas" y xenófobos en diferentes regiones del mundo han alcanzado cotas de poder no vistas desde décadas, y que nos remiten a un pasado que se ha pretendido, si no olvidar, sí mirar como parte de una historia de otro siglo que no debe volverse a repetir. En países como Austria, Holanda, Grecia, Estados Unidos, y un largo etcétera, partidos políticos que representan estas ideas se hallan muy cerca de hacerse con el poder, apoyándose en discursos que relacionan 
a la inmigración con la inseguridad ciudadana y el terrorismo, por un lado, y enfatizando las incidencias negativas que tienen los inmigrantes sobre la economía del país, por otro. El denominado Brexit, es decir, la próxima salida del Reino Unido de la Unión Europea, podría afirmarse que se sustenta, en buena medida, en ese "miedo al inmigrante".

La situación que se da en España es, cuanto menos, paradójica. De ser un país con unos saldos migratorios negativos, donde la gente predominantemente emigraba por motivos laborales, pasó a ser un país receptor y necesitado de mano de obra, por el auge económico y del sector de la construcción que se dio a partir de la década de los años 90 del siglo XX. Pero la súbita crisis económica que se inició en 2007 vino de nuevo a invertir esta tendencia. Todos estos cambios han tenido y tienen incidencia en las condiciones laborales y de vida, en las estrategias de subsistencia de la población inmigrante, y en la percepción que los autóctonos tienen sobre ella.

El texto que aquí se presenta es parte de una investigación realizada en España, en la comarca de la Vega Baja del río Segura ${ }^{3}$, cuyo objetivo es analizar la percepción que los diversos agentes sociales tienen sobre la crisis, el desempleo y la población inmigrante. Y es que, en este territorio, la crisis económica que desde hace años lleva afectando a España se ha notado especialmente, con una elevada destrucción de empresas básicamente pertenecientes al sector de la construcción, y en él se ha dado con inusual fuerza el fenómeno del estallido de la denominada "burbuja inmobiliaria", conllevando un aumento del paro y un empeoramiento de las condiciones de vida tanto de la población española como inmigrante. Pues se trata de uno de los lugares de España donde más viviendas se construyeron en los años de auge económico.

La comarca se encuentra al sur de la provincia de Alicante, en el levante español, y está formada por los 27 municipios distribuidos en una extensión de $957 \mathrm{~km}^{2}$. Cuenta con una población de 371212 habitantes, de la cual el 37,3\% es extranjera (INE, 2014). Esa población residente "migrada" o "foránea" la compone tanto población extranjera que busca trabajar, los denominados "inmigrantes", como población de residentes europeos, en su mayoría, de avanzada edad y provenientes del norte de Europa, que son de-

3 Esta comarca ha basado su economía tradicionalmente en la agricultura, pero el sector de la construcción, que ha ido ganando cada vez más suelo cultivable recalificado para la edificación, ha ido sustituyendo en las últimas décadas el trabajo del campo por la actividad inmobiliaria asociada al turismo residencial. 
nominados "turistas residenciales". Como sucedió en otras partes de España, los inmigrantes (laborales) empezaron a desplazarse a esta zona desde finales de la década de 1990 hasta $2006^{4}$, cuando existía una importante oferta de trabajo, puesto que el sector de la construcción estaba en auge y requería de mano de obra. Así, este sector se convirtió en el motor generador de empleo principal, donde se encontraban las mejores oportunidades laborales. Ante este fenómeno la mano de obra autóctona comenzó a ser insuficiente, por lo cual, los trabajadores inmigrantes empezaron a ocupar el excedente de puestos de trabajo que estaban surgiendo (González-Martín, Pumares y Rojas, 2012, p. 2). Tengamos presente que estos trabajadores inmigrantes de la construcción eran esencialmente hombres, por la división sexual del trabajo y las representaciones hegemónicas de género en esta sociedad. Como advierten algunos expertos:

En los años de expansión del sector, las condiciones laborales de los trabajadores mejoraron considerablemente. La abundancia de trabajo relajó el temor a no tener un puesto de trabajo (...). Las relaciones sociales que se desarrollaron durante este periodo estuvieron marcadas por la tranquilidad y la falta de rivalidad (...) Con la llegada de la inmigración las relaciones sociales en el sector sufrieron un cambio, aparecieron nuevos grupos. Los trabajadores inmigrantes, en general, fueron bien aceptados por los trabajadores autóctonos que no vieron peligrar sus puestos de trabajo (González-Martín, et al., 2012, p. 7).

El descenso de la tasa de natalidad en España y el rechazo por parte de la población autóctona, que cada vez mejoraba más sus condiciones de vida, a seguir desarrollando empleos que veían como "duros" y poco remunerados, entre ellos el trabajo en el campo, especialmente en la agricultura intensiva, la construcción y el trabajo doméstico, dieron lugar a uno flujos migratorios hacia este país sin precedentes. Originaria de países de América Latina, el este de Europa y el norte de África, la población extranjera se multiplicó por 10 en España entre 1996 y 2010, pasando de 542314 personas, que suponían el 1,4\% de la población total, a 5747734 que sumaban el 12,2\%, a la vez que el desempleo se reducía a niveles de la Unión Europea (Vázquez, 2012, p. 12).

4 Por su parte, los turistas residentes norte-europeos, comenzaron a llegar a esta comarca alicantina a partir de la década de 1980, con el auge del turismo de costa de este litoral mediterráneo. 
Este fenómeno migratorio adquirió un mayor impulso a partir de 1999, con la llegada de ecuatorianos y colombianos. En pocos años se situaron como el tercer y cuarto grupo de ciudadanos no comunitarios, ocupando puestos de trabajo que la población autóctona rechazaba y entrando en competencia directa con los ciudadanos magrebíes (Sempere, 2001). De la mano de la creciente demanda de trabajadores dentro del sector de la construcción, vino también la mejora sustancial en los salarios.

Pero, desde 2006 el sector de la construcción comenzó a resentirse por agotamiento, lo que, junto al problema de las hipotecas en Estados Unidos en 2007 y su repercusión en los entidades bancarias a nivel internacional, trajo una gran crisis mundial (González-Martín et al., 2012, p. 2). Esto precipitaría en España el estallido de la burbuja inmobiliaria y la súbita paralización del sector de la construcción con sus implicaciones en el empleo. De 1846100 parados en el año 2007 con una tasa de desempleo del 8,23\%, se pasó a 6051100 en 2013, lo que suponía un 26,1\% de paro. Más de dos millones de personas se quedaron sin empleo en apenas dos años, entre 2007 y 2009 (INE, 2015), y desde 2008 hasta 2013, año en que se vería superada sólo por Grecia, España encabezó los índices de paro de toda la Unión Europea (Eurostat, 2015).

Para algunos autores, el mercado laboral en España es un fiel reflejo de los problemas que se derivan de

La excesiva dependencia de sectores intensivos en mano de obra descualificada, como la construcción o la hostelería, de una inversión en políticas de bienestar que continúa siendo menor que en el resto de países europeos (Navarro, 2009), de unas elevadas tasas de temporalidad y desempleo, superiores al resto de la Unión Europea (...), y por último, de la importancia de la economía sumergida, incluso en los momentos de bonanza económica anteriores a la crisis (Arrazola et al., 2011, citado por Arnal, Finkel y Parra, 2013, p. 282).

Concretamente, en el sector de la construcción, la crisis económica ha tenido un enorme impacto, lo que ha traído consigo la pérdida de un elevado número de puestos de trabajo tanto de españoles como de extranjeros, y ha supuesto además un grave deterioro de las condiciones laborales. Sin embargo, como afirman algunos expertos: 
Al comparar la tasa de paro referente al ámbito nacional presentada por la población inmigrante y por la autóctona en dicho sector en 2009, observamos que la de los trabajadores extranjeros se había incrementado casi cinco veces respecto al año 2007, pasando del $8 \%$ al $37 \%$ (EPA, 2009). Igualmente, los datos reflejaban un aumento en la tasa de paro de los trabajadores españoles muy elevado, y, aunque se había multiplicado casi por cuatro en estos dos años (del 5,7\% en 2007 al 22,4\% en 2009), no alcanzó parámetros tan negativos como la de la población inmigrante (González-Martín, Pumares y Rojas., 2010 citado por González-Martín, et al., 2012, p. 2).

Estos datos evidencian que la crisis afectó con fuerza a la población inmigrante, esencialmente masculina, trabajadora en el sector de la construcción en España.

\section{Metodología}

Este artículo se encuadra en la investigación etnográfica llevada a cabo en el marco de diversos proyectos realizados desde julio de 2011 hasta la actualidad $^{5}$. Su objetivo es analizar cualitativamente, y con una metodología etnográfica basada en el trabajo de campo, la percepción de los españoles sobre la población extranjera, esencialmente inmigrantes laborales, a partir de la crisis y las altas tasas de desempleo que se dan desde hace varios años en la zona de estudio.

Las principales técnicas utilizadas han sido las fuentes documentales, la observación participante y la entrevista abierta. Para la selección de informantes hemos tenido en cuenta variables tales como: el sector económico, la situación laboral, la localidad, el sexo, el estado civil, la nacionalidad, la edad, etc. Hemos establecido cuatro tipologías de informantes entrevistados, que nos pueden transmitir información desde diferentes perspectivas: a) agentes de empleo, concejales y alcaldes ${ }^{6}$, b) empresarios; c) población en

5 El primero de estos proyectos de investigación en el que participamos fue subvencionada por la convocatoria de ayudas para el Fomento de Empleo (orden de la Consellería de Economía, Hacienda y Empleo de la Generalitat Valenciana, Pactos Territoriales para el Empleo, DOCV de 30 de diciembre de 2010) de acuerdo con el Plan de la Generalitat para el Impulso de la Economía y la Creación de Empleo, y solicitada por el Consorcio para el Desarrollo Económico de la Vega Baja (CONVEGA).

6 Como se trata de un grupo de fácil reconocimiento entre ellos, para preservar su anonimato hemos evitado especificar datos concretos sobre cada informante, $\mathrm{y}$ en las citas hemos optado por nombramos como informantes "tipo A. 
general (trabajadores asalariados, desempleados, amas de casa y jubilados, y d) sindicalistas y miembros de asociaciones (de agricultores, de empresarios, de inmigrantes, etc.).

Basándonos en estos datos exponemos algunos resultados de carácter cualitativo, ofreciendo citas literales de informantes.

\section{Inmigración laboral frente a turismo residencial}

En las últimas décadas se ha experimentado un elevado crecimiento demográfico en la comarca. La población se duplicó entre 1998 y 2013, pasando de 208138 habitantes censados en la comarca a 404 582. Este crecimiento se focalizó principalmente en la población extranjera, que se multiplicó por seis en apenas 12 años, pasando de 28253 personas en el 2000, a 176 448 en 2012, con un estancamiento a partir del año 2008 que coincide con la crisis y una disminución a partir de 2013, reduciéndose a 142226 habitantes en 2014 (INE, 2015).

Estos aumentos se deben fundamentalmente a los procesos migratorios, que, para autores como Mazón y Huete (2005, p. 115) y Díaz (2004, pp. 6-7) podríamos dividir en dos tipos:

1. Una inmigración por motivos laborales: procedente sobre todo de África, América Latina, los países del Este de Europa y China, que suelen trabajar en actividades como la agricultura, la construcción, la hostelería y los servicios domésticos7.

2. Una inmigración por motivos de ocio: procedente principalmente del centro y del norte de Europa y de otras comunidades del centro y del norte de España, que estaría integrada en gran parte por jubilados y formaría el colectivo de los denominados turistas residenciales.

Esta diferenciación es la que ha dado lugar a la dicotomía entre inmigrantes y turistas residenciales, que condiciona las percepciones que se dan sobre la población extranjera por parte de la población autóctona que en España y, en concreto, en la comarca.

7 Con la excepción de la población china, que desarrolla otros tipos de actividades, especialmente como propietarios de restaurantes, bazares, tiendas de ropa e hipermercados. 
La inmigración por motivos laborales ha sido ampliamente estudiada y debatida desde las ciencias sociales, y en este caso, se debe, principalmente, a la magnitud auge económico y a la enorme oferta de puestos de trabajo.

El término turista residencial resulta muy controvertido, pero es de frecuente uso en la literatura académica en lengua española. Mantecón (2008, pp. 130-131) recoge una serie de definiciones que aludirían a diferentes aspectos que nos permiten caracterizarlo: Para Vicente Rodríguez (2004, pp. 235-236) incluiría cuatro elementos fundamentales como la avanzada edad de estos turistas, la oscilación entre la migración permanente, temporal o la movilidad, la búsqueda de experiencias de ocio y los impactos que produce. López de Lera (1995, pp. 234-237) lo entendería como un flujo inmigratorio de jubilados europeos. Mazón y Aledo (2005, pp. 18-19) lo definirían como "la actividad económica que se dedica a la urbanización, construcción y venta de viviendas turísticas residenciales que conforman el sector extrahotelero, cuyos usuarios las utilizan para veranear o residir, de forma permanente o semipermanente, fuera de sus lugares de residencia habitual, y que responden a nuevas fórmulas de movilidad y residencialidad de las sociedades avanzadas". Cortina, Martínez y Varela (2002, p. 95) lo explican como un fenómeno relacionado con el uso de viviendas secundarias.

Su importancia es tal en la comarca, que si para el año 2014, el 37\% de la población de la comarca era de nacionalidad extranjera, de ésta, el 63\% era de la Europa Comunitaria, principal fuente de turistas residenciales.

La comunidad británica es la más numerosa con casi 50000 habitantes, es decir el 35\% de la población nacida en el extranjero. Los alemanes serían el segundo grupo más numeroso en cuanto a turistas residenciales y el tercero del total de extranjeros con casi 8000 habitantes, lo que supondría cerca de un $6 \%$. De este modo, británicos y alemanes conformarían los dos grupos principales de turistas residenciales.

La inmigración laboral, aunque en menor medida que el grupo anterior de extranjeros, también mantendría una presencia importante en la comarca, representada en primer lugar por los marroquíes, segundo mayor grupo inmigrante de la comarca, con casi 16000 personas, seguida de rusos (7 471), rumanos (5 439), búlgaros (5 246), ucranianos (3 991) y ecuatorianos (3 360), argelinos (2 397) y chinos (1 973). Dentro de la población rusa coexistiría la residente por motivos laborales con la que lo haría por motivos de ocio, si bien habría que tener en cuenta que en periodo de crisis muchos de los rusos que habían migrado por motivos laborales regresaron 
a sus países, aumentado proporcionalmente el número de turistas residenciales de esta nacionalidad.

Respecto a la localización geográfica, los denominados turistas residenciales se ubican principalmente en la zona litoral de la comarca o en los municipios colindantes.

En la zona de interior, predominarían los inmigrantes de origen marroquí y ecuatorianos, así como los de otros países de África y Latinoamérica, muchos de ellos antaño trabajadores de la construcción ahora en paro, de la agricultura, o de los servicios domésticos, en el caso de las mujeres.

\section{Incidencia de la crisis en la población inmigrante}

Con la llegada de la crisis en el año 2007 los residentes extranjeros en la comarca se vieron afectados de diferentes maneras.

Los europeos comunitarios, especialmente británicos jubilados, comenzaron a tener grandes dificultades para vender las viviendas que habían adquirido en la época de auge inmobiliario. Se trataba de viviendas en las que invertían sus ahorros, pensando que trataba de un valor seguro, que se iría revalorizando continuamente, y por las que obtendrían importantes beneficios en el caso de que tuvieran que venderlas. En la medida que iban envejeciendo retornaban a sus países de origen o fallecían sin haber podido recuperar su dinero. Igualmente el relevo generacional ya no se producía y la población británica se redujo considerablemente.

Los inmigrantes laborales sufrieron de un modo más acusado el comienzo de la crisis, siendo los hombres inmigrantes (principalmente rumanos, ecuatorianos, colombianos, marroquíes y argelinos) los primeros a los que las empresas de la construcción de esta zona despidieron en favor de los españoles, a los que se priorizaba a la hora de mantenerles el empleo. Si bien la caída del sector fue tan drástica que, en un breve lapso de tiempo, todos, con independencia del país de origen, se vieron afectados. En la actualidad algunos de estos grupos, sobre todo los marroquíes y ecuatorianos, han logrado mantener sus trabajos en el sector agrícola, aunque con peores condiciones laborales.

Por su parte, las mujeres inmigrantes, principalmente ecuatorianas y colombianas, copaban el ámbito de los cuidados y la limpieza en el contexto de economía sumergida y en trabajos considerados femeninos, por ser de “cuidados de personas y en el hogar". A lo largo de estos años fueron per- 
diendo su trabajo, pues la crisis y la falta de ingresos en muchas familias españolas han hecho que prescindan de sus servicios, al no poder asumir ese gasto. Y son ahora las mujeres de los grupos domésticos autóctonos quienes suelen desempeñar esas tareas del hogar y cuidados que antes hacían ellas.

Los rusos constituyen un caso aparte y han ido adquiriendo un nuevo status a raíz de la crisis. La caída de los precios de viviendas en España y la mejora de la economía de sus país de origen, los ha convertido en los "nuevos turistas residenciales", motivados por el clima, la playa, etc., así como por las garantías de seguridad y calidad de vida que les suponen residir en la Unión Europea. No obstante, la crisis de Ucrania y la devaluación del rublo en el año 2014 han creado un escenario con un futuro incierto, que se confirma con el descenso de compra de inmuebles de ciudadanos rusos (Prokopenko, 2014, p. 473).

Por último, los ciudadanos chinos a diferencia de lo que ha sucedido con los otros grupos de inmigrantes o con la población autóctona, ha seguido abriendo negocios y establecimientos comerciales que, aparentemente han ido funcionando. Aunque también se han visto afectados en algún grado por la crisis, factores relacionados con su cultura del trabajo pueden explicar su mayor competitividad en estos contextos de crisis.

\section{La bajada de los salarios}

Junto al desempleo, una de las consecuencias de la crisis económica ha sido la bajada de los salarios. Los casi diez años de crisis han cambiado la mentalidad sobre el trabajo, y los autóctonos aceptan trabajos y sueldos que eran impensables en otros tiempos, y que, en muchos casos los llevan al límite de la subsistencia. Y esto tiene repercusiones en las posibilidades de acceso al mercado laboral de las personas inmigrantes.

Son pocos los que mantienen su propio puesto de trabajo. Antes hacían tareas que los demás no hacían porque tenían otros puestos mejores, pero es que ahora la gente española trabaja por 500 o 400 euros al mes. Están dispuestos a hacer lo que antes no estaban dispuestos. Tenemos una subvención con el $\mathrm{INEM}^{8}$ que es de peones agrícolas que se paga por peonada, por jornada real realizada, que el salario es siempre inferior a otros convenios de otras subven-

8 Instituto Nacional de Empleo, desde 20013 se denomina Servicio Público de Empleo Estatal (SEPE), es un organismo autónomo adscrito al Ministerio de Empleo y Seguridad Social, del gobierno de España. 
ciones, como puede ser albañilería, etc., la persona a la que contratamos podía cobrar a lo mejor 800 euros al mes. Nos costaba Dios y ayuda conseguir que la gente que salía en los sondeos aceptara esa oferta. Ahora nos sobra la gente. Hay gente que 800 euros es lo máximo, con eso te trabajan las horas que haya que trabajar, el trabajo lo duro que sea (Informante tipo A).

Autores como García y Troncoso (2011, citados en Cea y Valles, 2014, pp. 230-231) han analizado, basándose en los registros administrativos de la Seguridad Social, la situación laboral de la población inmigrante en España en el inicio de la crisis, entre los años 2007-2009, poniendo de relieve que la crisis ha afectado, de manera especial, a los inmigrantes que han visto reducidas sus posibilidades de empleo y los salarios percibidos por su trabajo. Por ejemplo, en la franja de edad de 16 a 29 años el salario medio de un inmigrante era un $11,92 \%$ menor que el de un español, mientras que a edades superiores a 45 años la diferencia subía al 41,2\%, cifra que seguía incrementándose para puestos más cualificados. Al respecto nuestros entrevistados extranjeros nos solían dar argumentaciones del tipo siguiente:

Tengo que trabajar. En lo que sea. Y por lo que me den. Ahora pagan menos. Como soy marroquí no debo protestar. Ya llevo 12 años aquí, mi mujer, mis hijos...aquí... Yo siempre trabajando... en todo... ahora crisis y menos trabajo... a veces semanas sin trabajar...pero tengo que trabajar para vivir aquí (Hombre, 42 años, empleado, industria, marroquí, Callosa de Segura).

Mucho, nos ha afectado mucho a todos los inmigrantes. Aquí donde yo estoy trabajando a casi todos los que somos de Marruecos...nos dan menos dinero... Falta trabajo...y no quejarse, no debemos, nos echan, hay muchos esperando, se necesita a menos gente y hay muchos que quieren trabajar en el campo... en las fábricas...es mucha suerte seguir trabajando si no eres de aquí, ahora (Hombre, 36 años, empleado, agricultura, marroquí, San Fulgencio).

Y es que, efectivamente, como advierten Cea y Valles:

En este periodo de tiempo el paro se ha triplicado, tanto en la población española como en la foránea. Si bien, el incremento ha repercutido, de manera especial, en la población extranjera, que encuentran más oportunidades de empleo en los sectores más vulnerables al paro y donde las condiciones de trabajo son peores. Su tasa de paro llega al 36,02\% en 2012, trece puntos por encima de la población española; y se ha multiplicado por 2,96 (desde el 12,2\% en 2007 hasta el 36,02\% en 2012), a un ritmo similar al presentado 
por la población española (para la que se ha multiplicado por el 3,04: desde el 7,6\% hasta el 23,1\%) (2014, p. 232).

\section{El empeoramiento de las condiciones laborales}

A los sueldos inferiores hay que sumar el empeoramiento en general de las condiciones laborales de los inmigrantes en la zona estudiada. Como afirmaban nuestros informantes:

¡Bufff!...pues están los pobres inmigrantes explotados. Ahora mucho más que no hay apenas trabajo...A lo mejor cobran un par de euros al día y se matan a trabajar, no sé cuántas horas diarias pero una barbaridad. Las colombianas cuidando a ancianos...casi no les pagan...y sin contrato...jclaro! Por ejemplo en la huerta recogiendo la cosecha o lo que sea en ese tipo de trabajos sobre todo, de lo que yo conozco, están sin seguro y sin nada un montón de horas (Hombre, 26 años, desempleado, agricultura, español, Orihuela).

En efecto, una de las consecuencias ha sido el aumento de la economía sumergida en la comarca. Aunque este fenómeno existe en esta zona ya desde hace décadas (Téllez y Martínez Guirao, 2009), y que es muy difícil de cuantificar, hemos encontrado que, uno de los efectos directos que la crisis y el desempleo ha tenido, de modo significativo, en esta población inmigrante, es que ha incrementado el número de empleos sin contrato, sin declarar las horas extra, y muchos de los trabajos que estas personas desarrollan se hacen en el marco de la ilegalidad. Estas prácticas se adoptan, en parte, como una estrategia que permite la subsistencia de las empresas, al reducir los gastos en impuestos, pero del mismo modo suponen una pérdida de derechos para los trabajadores y los desprotege ante la posible explotación laboral, que también ha aumentado.

Muchos inmigrantes se dedican al sector inmobiliario en sus propios círculos, aunque la mayoría no está dada de alta. Otros inmigrantes trabajan fundamentalmente en la agricultura (rebotados del sector de la construcción) aunque creemos que en la gran mayoría de los casos lo hacen también sin dar de alta, en negro... ahora más que antes.... (Informante tipo A).

En la actualidad, un número significativo de la población inmigrante trabaja en el sector agrícola, donde, como se puede apreciar en la siguiente cita, la economía sumergida se halla muy presente: 
Los inmigrantes más en la agricultura y en los trabajos temporales, como mucho temporadas de 2 o 3 meses, y muchos de ellos se pagan el sello agrícola para tener la posibilidad de salir luego en los planes de empleo, que son planes nacionales que se hacen aquí a través del consejo comarcal. Entonces si le dan aquí dos meses y 25 días por ejemplo de empleo, con eso se pagan el sello todo el año, ganan casi tres mil euros y subsisten, y se pagan su sello, más algunas peonadas que hacen por ahí esporádicas de empresas de agricultura que los contratan y con eso van saliendo. Puede haber 60 inmigrantes en esa situación, y que no trabajen nada 40 . Y a lo mejor de estos que te digo como mucho son 20, los demás son ilegales, de que hacen horas por ahí esporádicas que los buscan los pequeños propietarios de tierra, mano barata casi gratis, no les costean la Seguridad Social pero los tienen a su disposición, sábado, domingo, ¡las horas que le da la gana!, hacen los trabajos de campo y los nacionales no tienen posibilidad porque ellos trabajan más barato (Informante tipo A).

En cualquier caso la idea generalizada entre la población local, en base a nuestras entrevistas, es que efectivamente, en estos últimos años, los inmigrantes ocupan en mayor medida los trabajos "en negro" y con peores condiciones y salarios.

Los inmigrantes se están llevando la peor parte de la crisis. Las mujeres, van a cuidar internos, sí que cogen ofertas de interna, o almacenes hortofrutícolas, porque además es que la española no va al almacén, y el hombre tampoco. Son trabajos muy duros, muy mal pagados. Además el hombre del almacén aunque sea español quiere inmigrantes, porque siempre le ha ido bien con inmigrantes, tienen su plantilla. Los españoles no están yendo, les planteas la idea y no van. A lo mejor tienen que desplazarse a Cox o a San Bartolomé y el sueldo dice que no les repercute. Además luego les dan de alta en el Régimen Agrícola que no es en el General y no lo terminan de ver. Es que hay mucha economía sumergida (Informante, tipo A).

\section{Emigración a otros destinos y retorno}

Otra consecuencia de la crisis en la población extranjera es que han emigrado a otros destinos. Este ha sido un aspecto que ha permitido mitigar la dureza de la situación de los inmigrantes (Cea y Valles, 2014, pp. 232-233). Según los datos del INE (2014) la población extranjera en la comarca representaba en el 2010 el 42,4\%, en 2011 el 42,6\%, en el 2012 el 43\%, en 
el 2013 el 42,8\% y en el 2014 descendió al 37,3\%. Así, mientras que en el 2010 había 167212 habitantes de nacionalidad extranjera en el 2014 el número de extranjeros en la zona es de 138469 habitantes, reduciéndose pues como vemos. Desde el 2012 al 2014 es significativo el abandono de alemanes y británicos, mientras que de Latinoamérica, las nacionalidades que más han acusado su salida de la comarca en estos años son los colombianos y los ecuatorianos. Por el contrario, en este periodo de 2012 a 2014, se aprecia un ligero aumento de población china y rusa.

El importante retorno de los británicos, como hemos comentado, obedece a que no se dé el relevo generacional, al haber dejado de ser rentable para ellos la adquisición de una vivienda en España.

Con respecto a los inmigrantes latinoamericanos que han regresado a sus países de origen, uno de los principales motivos es la falta de empleo y las aún paupérrimas condiciones de trabajo que se les presentan.

Hay menos aquí en el pueblo...menos colombianos, menos ecuatorianos y menos gente de por ahí. Se han tenío que ir. No tienen trabajo. Porque la mayoría de gente que no tiene trabajo está haciendo esos trabajos que antes no querían y les han dejao a ellos sin trabajo. ¡Claro! Aquí tú antes veías a un montón de gente con casas alquiladas. Gentes ecuatorianas, y eso...Y ahora, no ves a nadie (Mujer, 51 años, empleada, agricultura, española, San Miguel de Salinas).

Como afirman autores como Antón y Matarazzo (2015), este retorno no sólo se ha visto favorecido por las condiciones del país receptor, sino también dependen de los cambios sociales y económicos que se dan en los lugares de origen, como es el caso de la República de Ecuador.

En este sentido, nos repetían los entrevistados, que mientras que inmigrantes de otras nacionalidades regresaban a sus países de origen, los marroquíes, muy numerosos en ciertas localidades y que pueden llevar hasta dos generaciones viviendo ya en la comarca, si bien pueden ir a otras zonas de España e incluso a Marruecos temporalmente para trabajar, siempre regresan a ella.

El colectivo magrebí no, si no hay trabajo lo buscan fuera de aquí, pero su punto de retorno es aquí. Hay un colectivo importante casi de forma permanente, la mayoría de ellos con reagrupación familiar (han comprado una vivienda, o la tienen en alquiler más de 5-10 años). En julio y agosto salen para Marruecos, y el resto buscan el trabajo en este entorno y si no se van donde 
haya trabajo, si hay que irse a La Mancha, a Cataluña..., pero cuando acaban esas tareas automáticamente retornan (Informante tipo A).

Es más, si atendemos a los datos del INE (2015), la población procedente de África en la comarca que nos ocupa en 2014, lejos de haber descendido ha aumentado ligeramente en estos años, pues si en el 2012 había un total de 18133 personas africanas en 2014 esa cifra asciende a 19439 en 2014 . Esto se debe al continuo movimiento migratorio de magrebíes y subsaharianos que desde hace décadas, se trasladan a Europa en busca de trabajo y de mejores condiciones de vida, y ello a pesar de la actual "eurocrisis".

Con respecto a la población de origen asiático, principalmente pakistaníes y chinos, lejos de descender su número en estos años de crisis, podemos apreciar un ligero aumento. Así, en 2012 había un total de 3.172 habitantes procedentes de estas nacionalidades y en el 2014 ascendió su número a 4.061. Nos decían sobre ello nuestros informantes:

A todos los inmigrantes no les ha afectado el paro...no... a los chinos no. Los chinos van avanzando (...). Esos no se van, al contrario, no dejan de venir y ganan dinero, a pesar de la crisis. ¡Date una vuelta por estos pueblos y verás cuántos bazares chinos hay y restaurantes!...y wok...están por todas partes y les ha venido bien la crisis, tienen ventajas fiscales, no les controlan apenas (Hombre, 58 años, empresario, servicios, español, Benejúzar)

\section{Inmigración y percepción local}

Aunque tanto los datos estadísticos como la observación evidencian que los inmigrantes han sido un colectivo que se ha visto afectado especialmente por la crisis, en su vida laboral y en el cambio de opiniones de los nacionales sobre ellos, existe un percepción minoritaria por parte de algunos de nuestros entrevistados españoles que sugiere que los inmigrantes se han visto menos perjudicados (e incluso que a algunos les ha beneficiado en un mercado laboral competitivo capitalista). Se trata de una idea ambivalente que oscila entre el recelo y la empatía, y se sustenta en los discursos de que "ellos ya estaban desfavorecidos económicamente", o que en sus países de origen "ya habían vivido situaciones económicas que les había obligado a emigrar", frente a los españoles, "acostumbrados a un nivel de vida mucho mayor”, y que, por eso mismo, se ven ahora más afectados. 
A los de fuera les ha afectado como a todos (...). Pero yo creo que la crisis ha afectado más a los que más han tenido siempre. Una persona que ha sido pobre no puede haber notado tanto la crisis, de ahí que un inmigrante no creo que la haya notado tanto, en ese sentido (...) Pero bueno, es una crisis mundial: la estamos padeciendo todos (Hombre, 21 años, empleado, servicios, español, Orihuela).

La crisis nos afecta por igual (...) ahora estamos todos iguales de afectados. Bueno, ellos, los inmigrantes, están igual que estaban antes de venir (...) mal, pero nosotros hemos ido a peor (...) Hay gente de aquí, de esta comarca, que está comiendo en las casas de caridad, que han perdido sus coches y casas. (...) Sí que hubo una temporada que han trabajado muchos inmigrantes aquí, pero ahora es que no hay ni trabajo para los españoles (Mujer, 66 años, jubilada, servicios, española, Guardamar del Segura).

De la cita anterior se desprende la opinión generalizada que se muestra contraria a que haya españoles en paro y extranjeros trabajando y "ocupando" esos empleos que corresponderían, "por derecho", dicen, a la población autóctona. Estas ideas crean un ambiente de hostilidad ante lo que ven como una competencia desleal por un recurso escaso: el trabajo. Dirán algunos autores que otros estudios también revelan un deterioro de las relaciones intergrupales derivado de la situación de crisis, de los escasos puestos de trabajo ofertados, y de la creciente necesidad de los trabajadores de competir por ellos (González-Martín, et al., 2012, p. 4).

Existe en España, en el imaginario que se da sobre la inmigración y que se ha visto reflejado en nuestra investigación, la idea generalizada de que el objetivo fundamental del inmigrante a la hora de decidir desplazar su residencia. De este modo el binomio inmigración-trabajo se halla siempre presente a nivel ideático, retroalimentado por la crisis económica y por el olvido de las repercusiones positivas de la inmigración (Cea y Valles, 2014, pp. 226-227).

En palabras de Cea y Valles:

El eurobarómetro cualitativo (TNS Qual, 2011) también captó una pérdida de reconocimiento de la contribución de la inmigración al crecimiento económico del país, desde que comenzara la crisis económica. Aunque en conjunto (la población autóctona e inmigrante) comparta que los inmigrantes ocupan empleos que los locales no quieren, ya por sus características, ya por su salario, a su vez creen que ha de haber un equilibrio para que los inmigrantes "no quiten trabajo a los locales". Incluso algunos se sienten "amenazados" por el 
empleo inmigrante. De modo que la inmigración deja de percibirse "necesaria” (Bulgaria, República Checa, Estonia, Hungría, Letonia, Lituania, Malta, Países Bajos, Polonia, Eslovaquia y Reino Unido) (2014, p. 227).

Y no sólo no se ve como necesaria, sino que además, es muy usual la idea que defiende que la migración afecta negativamente tanto a los sueldos como a las tasas de empleo de los trabajadores de los países receptores. Idea que suele justificarse bajo el argumento de que los inmigrantes cuando llegan están dispuestos a trabajar con peores condiciones salariales, eludiendo los contratos laborales, rechazando derechos sindicales, etc., lo que los vuelve más competitivos, y por ello, más rentables para las empresas. Los trabajadores autóctonos se verán así desplazados, aumentando los índices de desempleo, a la vez que se producirán una reducción en los salarios (Sánchez, 2010, pp. 86-87, citado por Cea y Valles, 2014, p. 227). Igualmente, si un trabajador autóctono quiere acceder al mercado laboral tendrá que asumir las mismas condiciones que los inmigrantes.

En este sentido se pronunciaban nuestros informantes:

Es que es así, con tanto inmigrante en paro dispuesto a trabajar en cualquier cosa y casi sin cobrar nada...con salarios de miseria...no podemos hacer nada...Se llevan el poco empleo que haya...Aceptan que les exploten...y están aun así contentos por trabajar y ganar algo...Pero con eso no podemos vivir nosotros...y así los empresarios pagan menos a todo el mundo (Mujer, 60 años, empleada de hogar, española, Cox).

En nuestro estudio una gran mayoría de los españoles entrevistados defendía que, en un momento de crisis y desempleo como el actual en esta comarca, los inmigrantes compiten con los autóctonos, por lo que deberían "volver a sus países" para que el empleo lo obtengan los españoles. Este hecho era a su vez percibido por los trabajadores inmigrantes ${ }^{9}$ :

Hay mucho "moro" inmigrante trabajando sin contrato en las fábricas, en el campo, antes en la obra...y con esta crisis no cabemos todos...no hay empleo para todos...Pienso que nosotros estábamos aquí antes que ellos, y es

9 En otro estudio realizado en 2013 sobre la crisis y el desempleo, todos los integrantes de las muestras consideraban a los trabajadores inmigrantes como sus competidores, excepto entre los trabajadores más cualificados, predominando así el rechazo generalizado hacia ellos y siendo muy numerosas las manifestaciones que piden que se limite su participación en el mercado laboral en la actual situación de empleo (Arnal et al., 2013, p. 293). 
nuestro país, ¡se tienen que ir de donde han salido! (Hombre, 44 años, desempleado, industria, español, Albatera).

Me lo dicen hasta en el trabajo. Que el trabajo es para los del pueblo, no para nosotros, que tenemos nuestro país. Nos dicen ... que ya que estamos fuera de nuestra tierra, que no nos importará que nos vayamos a otro sitio a buscar trabajo, pero fuera de aquí, que apenas hay (Mujer, 29 años, empleada, servicios, ecuatoriana, San Miguel de Salinas).

En una investigación realizada por Ybarra y Stephan (1994), los autores señalaban la amenaza como predictor de reacciones negativas. Actualmente "la sensación de amenaza percibida por los trabajadores españoles está originando sentimientos y reacciones negativas hacia los trabajadores inmigrantes, quienes son percibidos por los autóctonos como un lastre para el sector" (González-Martín, et al., 2012, p. 13).

Los sentimientos negativos dan lugar a un empeoramiento de la imagen del inmigrante, que comienza a cargarse de prejuicios dando lugar a actitudes xenófobas.

Al respecto, nuestros inmigrantes entrevistados percibían ese empeoramiento de la imagen que los españoles de la zona tienen sobre ellos debido a la crisis y el desempleo, y nos contaban experiencias de familiares y amigos, o que ellos mismos habían vivido en primera persona:

Te ven como ladrona, que les quitas el pan de sus hijos...el trabajo...que compites por el trabajo que ellos pueden también hacer...te miran mal...te echan la culpa de que no haya trabajo... yo sí lo noto, y cada vez más....siempre tienen que buscar chivos expiatorios para todos los males ¿no? (Mujer, 37 años, empleada, industria, colombiana, Orihuela).

No obstante, los prejuicios varían en función del grupo étnico. A algunos colectivos se les relaciona con la delincuencia (por ejemplo los rumanos), a otros se les considera un peligro por las diferencias culturales y religiosas (por ejemplo los marroquíes), mientras que otros son vistos como responsables directos del cierre de muchas de las empresas locales (por ejemplo los chinos).

Los turistas residenciales son los menos perjudicados en este aspecto. Aunque es cierto que se dan posiciones críticas por la tendencia que tienen algunos de estos grupos a formar guetos, colonias (Jurdao, 1979) o enclaves (Williams et al., 1997), donde tienen sus propios negocios y comercios, efectuando entre ellos mismos las transacciones económicas, o que se valoran 
negativamente las implicaciones en los servicios sanitarios. No obstante, la opinión generalizada es que tienen efectos positivos para la economía local.

Algo similar sucede con los rusos, que con un alto poder adquisitivo, está comprando viviendas en la costa, aunque el hecho de que en la zona haya estado presente durante años la "mafia rusa" ha tenido influencias en el imaginario colectivo, colocándoles un estigma que los relaciona, en cierto modo, con la delincuencia.

El caso de los inmigrantes chinos merece mención especial por las reacciones y sentimientos paradójicos que se dan en torno a ellos por parte de la población local.

Se trata de un colectivo muy cerrado en relación con otros grupos étnicos, que mantienen la mayor parte de las relaciones sociales entre ellos, pero que igualmente, no suelen entablar relaciones conflictivas con la población local. Desde la década de 1990 fueron abriendo establecimientos de comida china por toda la comarca, al igual que sucedía por el resto de la geografía española. Posteriormente fueron diversificando sus actividades económicas, que ofrecían productos importados de China a unos precios mucho más asequibles que los comercios autóctonos. Pronto entraron en competencia directa con industrias de la provincia de Alicante y de la comarca. Tal es el caso de la industria juguetera de Ibi, o la del calzado de Elche que tenía especial repercusión en la economía de esta zona y que sufrió una importante crisis en el año 2004, cuando se dieron episodios xenófobos que desembocaron incluso en que se incendiara una nave de calzado de propietarios chinos (Cachón, 2006). Estos brotes no perduraron en el tiempo, aunque sí los comentarios y prejuicios xenófobos, en parte relacionados con un etnocentrismo y choque cultural provocado por concepciones distintas del trabajo. Estos prejuicios giran alrededor de ideas como que son una comunidad cerrada, la competencia desleal, los horarios excesivos de trabajo, el no respeto a los derechos laborales, el vivir hacinados en el lugar de trabajo, la calidad deficiente en los productos, el plagio, etc. Para autores como Beltrán y Sáiz (2001, p. 3), esta percepción, junto a otros factores, estaría relacionada con aspectos culturales del trabajo. Desde la concepción china del trabajo, por ejemplo, la actividad económica debe basarse en la familia, el empleador chino ha de proporcionar alojamiento a sus empleados, o los trabajadores prefieren concentrar su actividad laboral en unos pocos años y acceder a la jubilación a una edad más temprana (Petit, 2002, pp. 327-328). 
Las actuaciones paradójicas por parte de la población autóctona se dan desde el momento en que los mismos que los critican acuden a establecimientos chinos a realizar sus compras, por los precios económicos, alegando a que es una estrategia doméstica para poder subsistir en tiempos de crisis.

Pero los negocios regentados por población inmigrante no son exclusivos de la población china. Como ya hemos señalado, los turistas residenciales ofrecen sus servicios y crean establecimientos comerciales para ellos, y otros grupos étnicos suelen administrar negocios también para inmigrantes. Son relativamente frecuentes los restaurantes ecuatorianos y colombianos, sobre todo en zona de costa, los locutorios y los establecimientos de comida halal dirigidos a la población de origen árabe. Pero estos no son percibidos desde la población autóctona como una amenaza para su subsistencia económica.

La diferencia estriba en los números ejemplos, que persisten en el imaginario colectivo, de empresas y establecimientos que han tenido que cerrar sus puestas al entrar en competencia directa con los negocios chinos, hecho que se sigue retroalimentando con cierta frecuencia.

Se ha de advertir que en esta comarca estudiada se percibe como un problema latente el tema de la xenofobia y el racismo y sus posibles brotes, que pueden provocar situaciones de competencia por el trabajo entre nacionales españoles y población inmigrante.

No tengo datos cuantitativos pero aquí, al contrario de lo que sucede en municipios vecinos, donde hay turistas residenciales, lo que tenemos son ciudadanos del Este de Europa y marroquíes, que hasta ahora venían aquí porque había trabajo en la construcción, en el campo, etc., y ahora el problema que tenemos es que si no hay para los de aquí, pues para ellos lo mismo o menos. Algunos siguen trabajando en el campo y en labores puntuales, en trabajos duros, pero es increíble el gran número de personas inmigrantes que vienen aquí al ayuntamiento a pedir subsidios, ayuda, comida, etc. Eso plantea actualmente un problema gravísimo, porque aunque sabemos que tenemos que ayudar a todo el mundo por igual y que son vecinos de aquí, pero la desesperación de los vecinos autóctonos de aquí, pues muchas veces, no ha habido ningún problema ni de racismo ni nada, pero sí se escuchan los típicos comentarios de que a éste lo han cogido para trabajar en el ayuntamiento y a nosotros no, o habiendo gente del pueblo vienen estos a... Entonces eso espero que no llegue a más, pero a pequeña escala sí se están viendo situaciones de este tipo, ya te digo que no ha habido ningún problema físico ni con- 
creto, pero la gente está muy desesperada y yo entiendo que los políticos ahí tienen un problema, porque no saben cómo resolverlo (Informante tipo A).

Por el contrario, en una cuarta parte de las respuestas en las entrevistas a españoles que hemos llevado a cabo, se defendía al colectivo de inmigrantes y se criticaba a las opiniones xenófobas que se oyen:

Yo te podría decir la tónica general de los comentarios de la gente del pueblo. Son tradicionales: -'es que los inmigrantes están quitando el trabajó-. No. Es que tú le estás dando una salida mejor a tu hijo, entonces alguien tiene que realizar esa labor, y encima, con un sueldo precario. Es que cuando fue el boom de la construcción se estaba muy bien y se ganaba mucho dinero en la obra. Ahora que no hay construcción todo el mundo quiere regresar a su puesto de trabajo. Y están explotando a los pobres inmigrantes, que encima de tener puestos y sueldos precarios y malos, encima tienen que aguantar algunos comentarios. Y son sus hijos [de los inmigrantes] los que nos van a sacar a nosotros, si tenemos algún tipo de pensión en el futuro. Cuantos más hijos tengan, más impuestos pagarán, y se podrán pagar nuestras pensiones (...) Las personas inmigrantes tienen un papel principal en la economía del pueblo (Mujer, 25 años, desempleada, servicios, española, Dolores).

En cualquier caso, la crisis y el desempleo están modificando las relaciones interpersonales entre empleadores (empresarios) y empleados (trabajadores), entre españoles y extranjeros. Si bien, en España, a diferencia de lo que está sucediendo en otros países, las ideas xenófobas y el "miedo al inmigrante" no están teniendo un reflejo claro en la política. Los partidos "tradicionales", con independencia de la ideología que los sustente, suelen evitar los comentarios negativos hacia las personas inmigrantes, y cuando lo han hecho, ha sido en un tono mucho más sutil que los nuevos partidos políticos que están triunfando en otros lugares. Por su parte, los partidos emergentes basan sus campañas políticas en la lucha contra el desempleo y la corrupción, donde la inmigración no suele presentarse como un problema de importancia.

Es cierto que existen otros debates sobre los inmigrantes, como si aquéllos que se encuentran en una situación "irregular" deben tener o no acceso a la "sanidad universal", que han provocado reacciones diversas, muchas de ellas de apoyo a estas personas. También es evidente que la crisis ha aumentado las reacciones xenófobas, pero lo ha hecho de una manera contenida, 
y habrá que esperar, entre otros aspectos, al desarrollo de la economía para conocer cómo se resuelve la situación.

\section{Reflexiones finales}

Tal y como hemos ido viendo en el texto, la situación de elevado desempleo en esta comarca provocado por la crisis económica, y de modo especial, su efectos en el sector de la construcción, ha repercutido de manera notable en la población inmigrante.

Si bien hasta finales de la pasada década los inmigrantes eran bien vistos por los locales, pues venían los hombres a trabajar en el campo y en la construcción, y las mujeres en el cuidado de personas y en ciertas fábricas esencialmente, esta percepción ha cambiado y con ella la interacción social, al verse ahora al colectivo de inmigrantes como "competidores" en el mercado laboral.

Podríamos afirmar que esta crisis ha afectado de manera bastante más severa a la población inmigrante, que, en muchos casos, al perder el trabajo o ver significativamente empeorado su salario o las condiciones laborales, engrosando de modo especial las filas de la economía sumergida, se han visto obligados a abandonar la comarca y volver a emigrar en busca de empleo.

No obstante, a pesar de ello ha habido un empeoramiento de la imagen de la población inmigrante para los autóctonos, que se debaten entre argumentos contradictorios. Si por un lado, recuerdan, por ejemplo, la llegada hace más de una década a estos municipios de población proveniente del norte de África (hombres para trabajar en el campo o la construcción) o de Latinoamérica (mujeres para ocupar trabajos como el cuidado de ancianos, enfermos y niños), y los efectos positivos que esto tuvo para la comarca; por otra parte, esgrimen al mismo tiempo ahora que "el trabajo ha de ser para los de aquí".

Resulta evidente la complejidad del comportamiento humano y las representaciones ideáticas, con sus paradojas, ambigüedades y contradicciones, que se suelen acentuar en momentos de crisis y de cambio social. Del mismo modo, el mundo globalizado en el que vivimos puede hacer que acontecimientos que suceden en otros lugares tengan incidencia en los procesos migratorios, y en las percepciones locales sobre los inmigrantes diferentes nacionalidades. Procesos como, por ejemplo, la prosperidad eco- 
nómica de Rusia o la posterior guerra de Ucrania, el terrorismo yihadista, enfermedades localizadas geográficamente como el zika o el ébola, decisiones políticas como el Brexit, etc., pueden modificar tanto el status como los imaginarios sobre la inmigración en ámbitos locales, y nos plantean un futuro tan dinámico como incierto.

\section{Bibliografía}

Antón Hurtado, F. \& Matarazzo, C. (2015). Invirtiendo la ruta: procesos de retorno de los ecuatorianos en España. Universitas, XIII (23), 35-64.

Arnal, M., Finkel, L. \& Parra, P. (2013). Crisis, desempleo y pobreza: análisis de trayectorias de vida y estrategias en el mercado laboral. Cuadernos de Relaciones Laborales, 31(2), 81-311. Recuperado de http://revistas.ucm. es/index.php/CRLA/article/viewFile/43221/40971

Arrazola, M., de Hevia, J., Mauleón, I., \& Sánchez, R. (2011). Estimación del volumen de economía sumergida en España. Cuadernos de Información Económica, 220, 81-88.

Beltrán, J., \& Sáiz, A. (2001). Trabajadores y empresarios chinos en Cataluña. Barcelona: Universitat Autònoma de Barcelona.

Cachón, L. (2006). Intereses contrapuestos y racismo: el incendio de los almacenes chinos en Elche (septiembre de 2004). Circunstancia, 4(10), 1-19.Mayo.

Cea, M. Á., \& Valles, M. S. (2014). Evolución del racismo, la xenofobia y otras formas conexas de intolerancia en España. Ed. Subdirección General de Información Administrativa y Publicaciones, Ministerio de Empleo y Seguridad Social http://explotacion.mtin.gob.es/oberaxe/inicio_descarga Fichero?bibliotecaDatoId $=4056$

Cortina, F., Martínez, A., \& Varela, B. (2002). Aproximación a la investigación del alojamiento privado de uso turístico. Estudios turísticos, 151, 87-97. Instituto de Estudios Turísticos.

Díaz, F. (2004). La Costa Blanca: el crecimiento a ninguna parte. En: IX Jornadas de economía crítica sobre perspectivas del capitalismo a escala mundial: ¿más destrucción económica y más regresión social? Madrid, 25 a 27 de marzo de 2004. Madrid: Facultad de Ciencias Económicas y Empresariales.

García, I., \& Troncoso, D. (2011). La inmigración en el mercado laboral español: ¿qué ha cambiado entre 2007 y 2009? En: E. Aja, J. Arango, y J. Oliver, Inmigración y crisis económica. Impactos actuales y perspectivas de fu- 
turo. Anuario de la Inmigración en España. Edición 2010 (pp. 210-251). Barcelona, Fundación CIDOB: Bellaterra.

González-Martín, B., Pumares, P., \& Rojas, A. J. (2010). El “colapso” del sector de la construcción y sus repercusiones sociolaborales sobre la población inmigrante. Análisis de las fuentes estadísticas. Sevilla: Fundación Pública Andaluza Centro de Estudios Andaluces, Consejería de la Presidencia, Junta de Andalucía.

(2012). El impacto de la crisis de la construcción en las relaciones intergrupales dentro del sector. Revista Gazeta de Antropología, 28(2). Recuperado de http://www.gazeta-antropologia.es/?p=1220

Instituto Nacional de Estadística (INE) (2015). Revisión del Padrón 2012 y 2014. http://www.dip-alicante.es/documentacion/4hogares.asp?codigo=00034

Jurdao, F. (1979) España en venta. Compra de suelos por extranjeros y colonización de campesinos en la Costa del Sol. Madrid: Ed. Ayuso.

López de Lera, D. (1995). La inmigración en España a fines del siglo XX. Los que vienen a trabajar y los que vienen a descansar. Revista Española de Investigaciones Sociológicas, 71-72, 225-245.

Mantecón, A. (2008). Procesos de urbanización turística. Aproximación cualitativa al contexto ideológico. Papers, 89, 127-144.

Mazón, T., \& Aledo, A. (2005). El dilema del turismo residencial: ¿turismo o desarrollo inmobiliario? En: T. Mazón y A. Aledo, Turismo residencial y cambio social. Nuevas perspectivas teóricas y empíricas (pp. 11-31). Alicante: Editorial Aguaclara.

Mazón, T., Huete, R. (2005). Turismo residencial en el litoral alicantino: los casos de Denia, Altea, Benidorm, Santa Pola y Torrevieja. En: T. Mazón y A. Aledo, Turismo residencial y cambio social. Nuevas perspectivas teóricas y empíricas (pp. 105-138). Alicante: Editorial Aguaclara.

Navarro, V. (Dir.) (2009). La situación social en España (Vol.3). Madrid: Biblioteca Nueva.

Petit, A. (2002). Una mirada a la comunidad china desde Occidente. Cuadernos de Geografía, 72, 321-336.

Prokopenko, Y. (2014) Evolución del flujo turístico ruso y su importancia económica: el caso de la Costa Blanca. (Tesis doctoral). Instituto Universitario de Estudios Turísticos. Universidad de Alicante. España.

Rodríguez Rodríguez, V. (2004). Turismo residencial y migración de jubilados. En: J. Aureoles (Coord.), Las nuevas formas de turismo, monográfico de la revista Mediterráneo Económico, 5. Caja Rural Intermediterránea. Cajamar. 
Téllez, A. y Martínez Guirao, J. E. (2009). Crisis, mujeres y economía informal: condicionamientos ideológicos de género en los sectores productivos del calzado y el juguete en la provincia de Alicante. En: A. Téllez y J.E. Martínez Guirao (Eds.), Economía informal y perspectiva de género en contextos de trabajo. Barcelona: Icaria.

TNS Qual (2011). Migrant integration. Aggregate Report. Qualitative Eurobarometer. European Commission. Directorate-General Home Affairs and coordinated by Directorate-General for Communication.

Sánchez, J. J. (2010). Socioeconomía de las migraciones en un mundo globalizado. Madrid: Biblioteca Nueva.

Sempere, J. D. (2001). Latinoamericanos y magrebíes en el medio rural. Las provincias levantinas. Scripta Nova. Revista Electrónica de Geografía y Ciencias Sociales. Migración y cambio social, 94(91). Recuperado de http:// www.ub.edu/geocrit/sn-94-91.htm

Ybarra, O. J. y Stephan, W. G. (1994). Amenaza percibida como predictor de prejuicios y estereotipos. Reacciones de los americanos a los inmigrantes mejicanos. Boletín de Psicología, 42, 39-54.

Vázquez, P. (2012). Los efectos de la inmigración en España. Nueva Revista de Política, Cultura y Arte, 107. Recuperado de http://www.nuevarevista. net/articulos/los-efectos-de-la-inmigraci\%C3\%B3n-en-espa\%C3\%B1a

Williams, A., King, R., \& Warnes, A. (1997). A place in the sun: International retirement migration: new format of an relationship in southern Europe. European Urban and Regional Studies, 4(2), 115-134.

Fecha de recepción: 19/10/2016; fecha de aceptación: 28/11/2016; fecha de publicación: 30/06/2017 